\title{
Low cost propulsion systems for the developing world
}

\author{
Tanay Sharma* \\ Dept. of Engineering \& Design \\ University of Sussex \\ Brighton, United Kingdom \\ Rupert Young \\ Dept. of Engineering \& Design \\ University of Sussex \\ Brighton, United Kingdom
}

\author{
Chris Chatwin \\ Dept. of Engineering \& Design \\ University of Sussex \\ Brighton, United Kingdom \\ Philip Birch \\ Dept. of Engineering \& Design \\ University of Sussex \\ Brighton, United Kingdom
}

Abstract - Space has often been referred too as the final frontier. It is the curiosity of what lies beyond our planet that drives us to turn to the skies. This quest for knowledge and the chance of travelling to the heavens has compelled people to devote their lives to space science, innovation and analysis of our everexpanding universe. Today the most significant impact of rocketry comes in the form of manned spaceflight. Vehicles like the Space Shuttle and Soyuz began the trend of greater commercialization of manned rocketry, enabling widespread access to space.

Whilst the curiosity of what lies beyond may have propelled the development of the space tourism industry, its current operational cost is estimated as $\mathbf{\$ 2 0} \mathbf{\$} \mathbf{2 8}$ million per passenger per flight. Although the vision of providing low cost space travel still exists, its application is hindered by the costs associated with current space vehicles and mission operations. Furthermore, if we are to better understand our universe and are keen on commercializing space, we would require the space tourism industry to operate in a similar fashion to the aviation industry. As most current launch vehicles rely on chemical propulsion, the level of uncertainty in the market drives their fuel costs. In order to reduce the cost per flight, we must effectively increase the load factor per flight and operate multiple flights, enabling a greater number of paying passengers. In order to provide widespread access to space there needs to be a greater emphasis on the research and development of low cost Reusable Launch Vehicles (RLV) which predominantly rely on alternative fuel technologies, thereby reducing the overall cost per flight. Although progress would be slow, we would still be able to witness a boom in space tourism.

This paper proposes the use of magnetic levitation and propulsion (Maglev) within a vacuum chamber as a viable lowcost propulsion technology. It aims to prove that such a system is capable of providing adequate thrust to future space vehicles. As Maglev systems allow for horizontal take-off and landing, such a launch system could be used in conjunction with current airports worldwide. Although the inception and creation of such a system may seem expensive, the long-term fiscal costs are relatively lower than current day systems. This is primarily because such a system relies on electrical power, whose supply and generation costs are much lower than that of chemical propellants. Also, the maintenance costs associated with the Maglev track are minimal, as during take-off there is no physical contact between the track and the launch vehicle.

Similar to the aviation industry, the success of future space exploration programs and space tourism relies on international cooperation and alliances. This not only ensures that no one country dominates access to space, but also nurtures healthy competition by providing a level playing field. By implementing the afore mentioned system in politically stable developing nations, we ensure employment, innovation and motivation, all achieved through an international alliance. This system would not only ensure a faster urban development within these countries, but would also bring the vision of space science and exploration to a larger global audience.

This paper discusses the overall cost analysis for a vacuum operated Maglev system, the various options available for the generation of power required by such a system and how the system's long term costs can be aligned with the aviation industry.

\section{INTRODUCTION}

Space exploration has long been a symbol of national pride for many countries, and a method of demonstrating technical achievement to the rest of the world. However, space exploration and research are an extremely expensive venture. As a result, only a handful of agencies backed by wealthy, economically stable nations seem capable of conducting cutting edge research. While all scientific research is dependent on cooperation that crosses physical and political boundaries, international cooperation is extremely important in space research. Although cooperation in space scientific research has been commendable, there are still obstacles that hinder full participation of scientists from developing countries. Researchers from such countries often encounter difficulties in fully participating and integrating with the international scientific community, in part due the limited resources at their disposal and because space science is not necessarily high up the national agenda. 
One of the key problems faced today is the 'brain-drain' from developing to developed nations, resulting in the loss of highly skilled human resources. It is essential that efforts be made to promote awareness among local authorities and the public in developing nations of the importance of space science, thereby ensuring that researchers are provided with basic resources necessary to conduct their work. In the current economic scenario, we are witness to the largest ever-global crisis. Nations, that one seemed economically stable and immune to the growing pandemic are now trying to do everything possible to prevent a massive recession. The unemployment rates in these nations have skyrocketed and their local economies are crumbling. Countries that have already spent billions on saving banks and industries are now looking to bolster their position. Their downturn on spending will also affect the scientific community, especially space science. Space is a unique industry; it belongs to no one and as such belongs to everyone. It is one that has fascinated every human; one where the international community collaborated despite their differences, and one that has great potential. However in the long term, current space systems like the Space Shuttle would not be economically and politically viable. Furthermore in order to provide widespread access to space, and help develop the growing space tourism market we need to find a viable partnership between the private and public sector. We exhibit a tendency to overestimate the amount of money spent on space exploration and research and underestimate the money spent on defense and social programs. Fig 1. illustrates NASA's long-term affordability in terms of millions of dollars up until 2020[1], while Table 1. represents the presidential budget request for 2009 for NASA's space operations until 2013[2]. It is vital to remember that NASA's annual budget amounts to just over $\$ 16$ billion. To put this into perspective, the United States spends over $\$ 1.14$ trillion on social programs each year, which amounts to just over $\$ 3807$ per person per fiscal year. In comparison the US space program costs an average of $\$ 53$ per person per fiscal year.

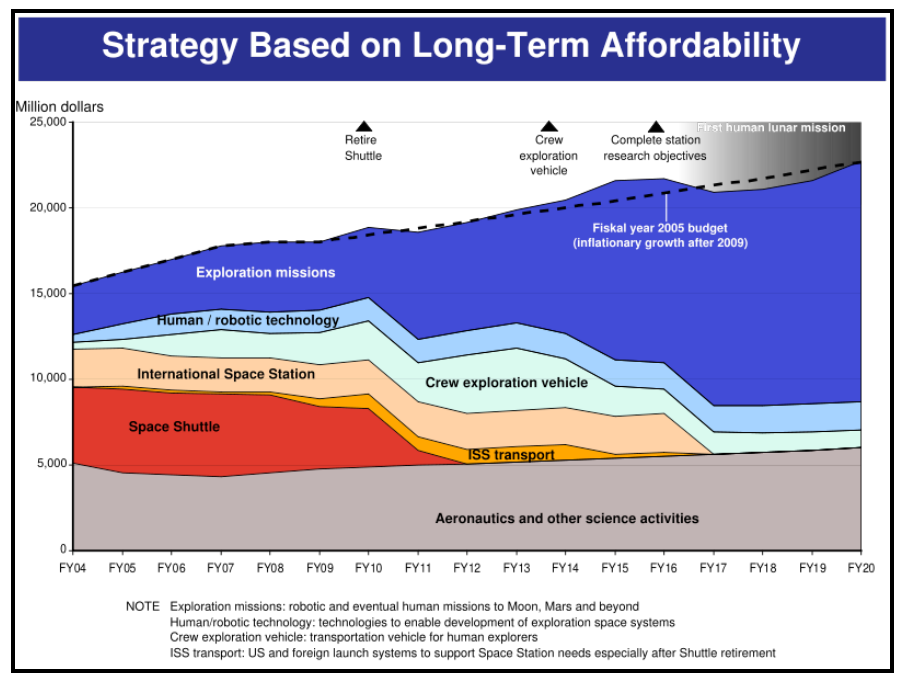

Figure 1. NASA budget projections (FY2004 - FY2020)
TABLE I. NASA FY08 AND FY09 BUDGET SUMMARY

\begin{tabular}{|c|c|c|c|c|c|c|c|}
\hline Budget Authority (\$ millions) & $\begin{array}{r}\mathrm{FY} 2007 \\
\text { Actual }\end{array}$ & $\begin{array}{l}\text { FY } 2008 \\
\text { Enacted }\end{array}$ & FY 2009 & FY 2010 & FY 2011 & FY 2012 & FY 2013 \\
\hline $\begin{array}{l}\text { FY 2009 President's Budget } \\
\text { Request }\end{array}$ & $5,113.5$ & $5,526.2$ & $5,774.7$ & $5,872.8$ & $2,900.1$ & $3,089.9$ & $2,788.5$ \\
\hline Space Shuttle & $3,315.3$ & $3,266.7$ & $2,981.7$ & $2,983.7$ & 95.7 & -- & - \\
\hline International Space Station & $1,469.0$ & $1,813.2$ & $2,060.2$ & $2,277.0$ & $2,176.4$ & $2,448.2$ & $2,143.1$ \\
\hline Space and Flight Support (SFS) & 329.2 & 446.3 & 732.8 & 612.1 & 628.0 & 641.7 & 645.4 \\
\hline $\begin{array}{l}\text { FY } 2008 \text { President's Budget } \\
\text { Request }\end{array}$ & $6,108.3$ & $6,791.7$ & $6,710.3$ & $6,625.7$ & $3,036.6$ & $2,978.0$ & - \\
\hline Space Shuttle & $4,017.6$ & $4,007.5$ & $3,650.9$ & $3,634.4$ & 116.2 & -- & - \\
\hline International Space Station & $1,762.6$ & $2,238.6$ & $2,515.1$ & $2,609.2$ & $2,547.5$ & $2,600.8$ & - \\
\hline Space and Flight Support (SFS) & 328.1 & 545.7 & 544.3 & 382.0 & 372.9 & 377.2 & - \\
\hline $\begin{array}{l}\text { Total Change from FY } 2008 \\
\text { President's Budget Request }\end{array}$ & -994.7 & $-1,265.6$ & -935.6 & -752.9 & -136.5 & 111.8 & $2,788.5$ \\
\hline
\end{tabular}

In order to better understand space, enhance technological achievement and bring space exploration to the masses there needs to be a better integration between the developing and developed nations. In order to provide a cost effective service, we propose the development of a vacuum based magnetic levitation and propulsion system. Such a system is terrain and weather independent, has a smaller carbon footprint, lower maintenance costs and is extremely safe and reliable. The system requires an external energy source, which can be generated using solar, wind or nuclear power [3]. The implementation of such a system in developing nations would not only help stabilize their economies but would also bring other benefits such as employment, medical and educational infrastructure, better global cooperation for research and development, tourism etc. Furthermore, in order to align such a system with the current aviation industry we must ensure that the cost of power per launch is much lower than the current air turbine fuel (ATF) prices.

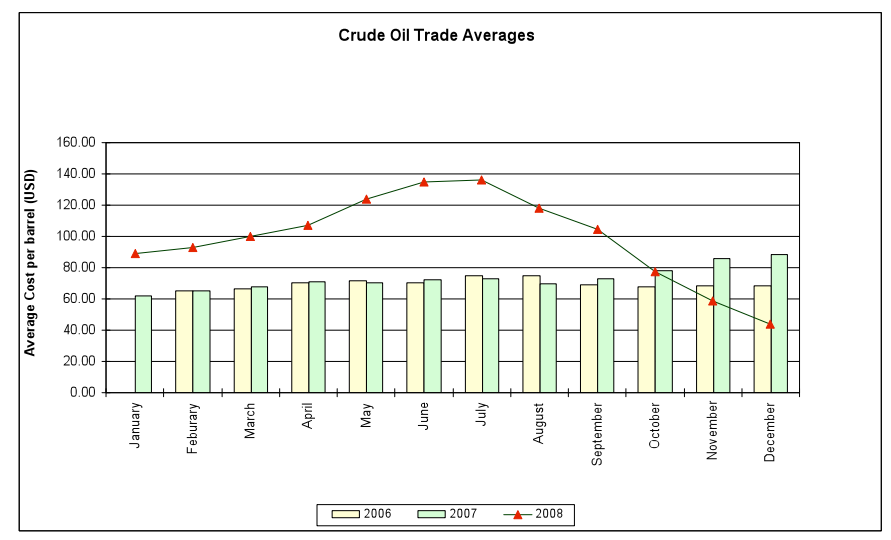

Figure 2. Crude oil trade averages

Fig. 2 shows a representation of ATF prices over the last three years. As we can see, the cost of ATF or jet fuel dropped below $\$ 40$ per barrel towards the end of 2008. Fig. 3 is a graphical representation of actual world oil prices from 1980 to 2008 and speculative prices from 2008 until 2030. It represents a high/low and reference case for each year, which clearly indicates the instability in the market over the last 12 months. It also puts into perspective the uncertainty in the years to come. Bearing that in mind, in order to make new oil exploration economically viable the average cost per barrel needs to be in the range of $\$ 70-\$ 80$ per barrel. The fourth quarter results for 
2008 show average cost per barrel rapidly declining below $\$ 80$ and stabilizing at an average of $\$ 43.75$ in the beginning of the first quarter of 2009. This rapid decline in crude oil averages has already led to new exploration projects being shelved in Canada, USA, Mexico and Damman. In order for us to succeed in developing a low cost propulsion system for the developing world, we must not only ensure that our cost per pound to orbit is lower than current space vehicles but also that our cost per seat undercuts the aviation industry, enabling us to dominate the commercial market as well.

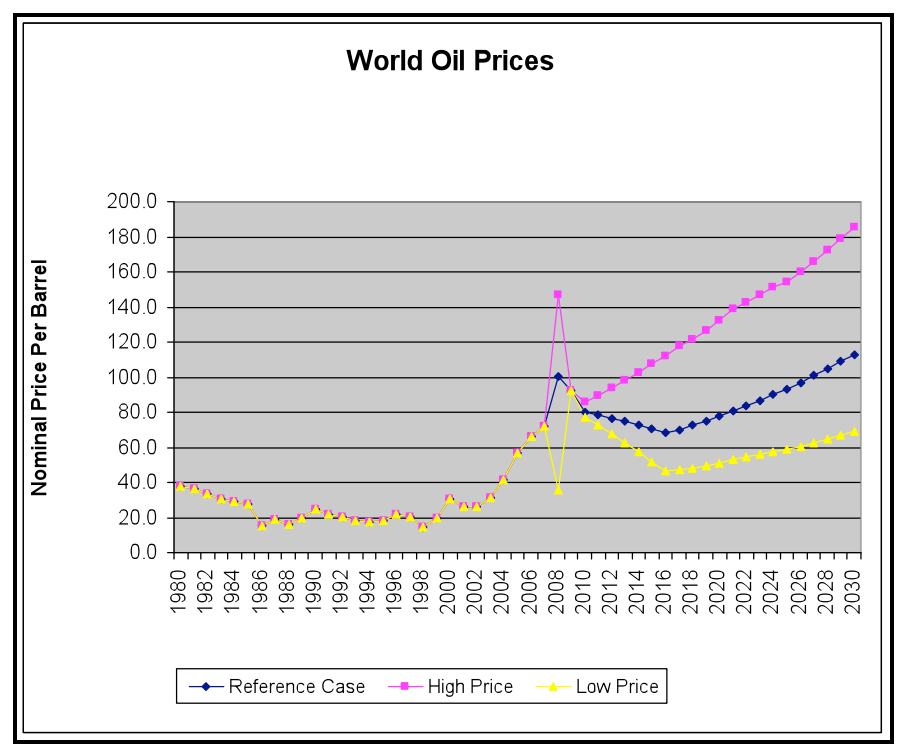

Figure 3. World oil prices - three reference scenarios

\section{Proposed PropUlsion SYSTEM}

All current Maglev systems are in theory designed as openair systems. As such these systems are subject to both electrodynamic and aerodynamic drag. While the electrodynamic drag is negligible at high speeds, the aerodynamic drag faced quadruples every time the crafts velocity doubles. Therefore the power required to overcome the drag is eight times the original value for effective increase in velocity. The frictional drag faced by the vehicle during a horizontal launch would also lead to a large increase in the surface temperature at the vehicles extremities, which may damage various internal components. As a result the maximum speed of current day ground transport systems operating on the Maglev principle is capped at $350 \mathrm{mph}$. The aerodynamic drag faced by such a system is proportional to the air density, hence by reducing the air density coming in contact with the launch vehicle, we lower the amount of power required to overcome the drag. In order to overcome the drag and create a reliable and economically viable system, we propose the use of superconducting Maglev technology inside a purpose built vacuum tunnel approximately five miles long, allowing us to achieve initial launch velocity with a reusable launch vehicle (FRLV) [3]. Fig.4 illustrates the launch vehicle levitated over the guideway whilst Fig. 5 shows a wireframe view of a horizontal launch approach.

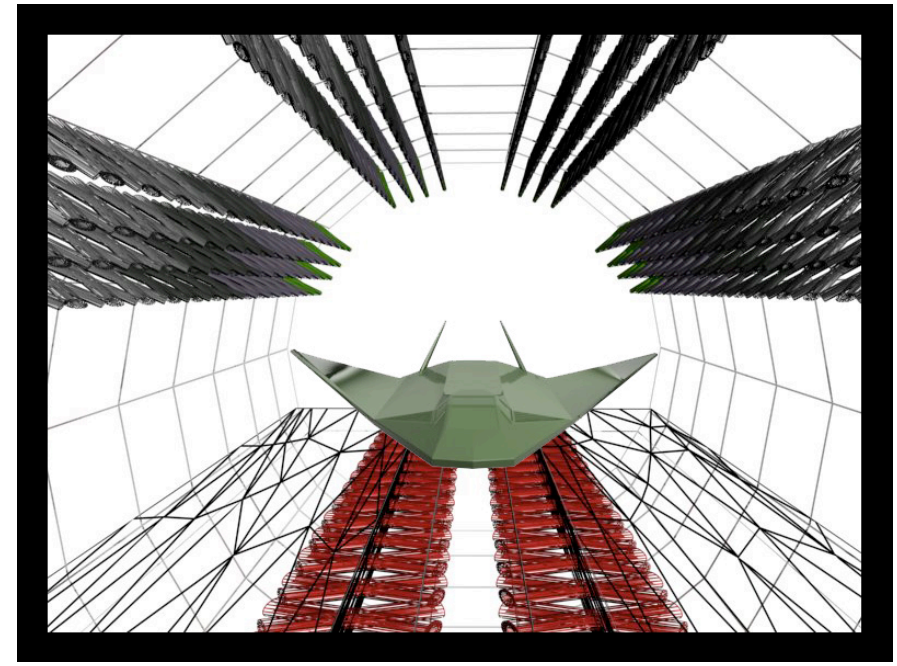

Figure 4. Launch system and craft design

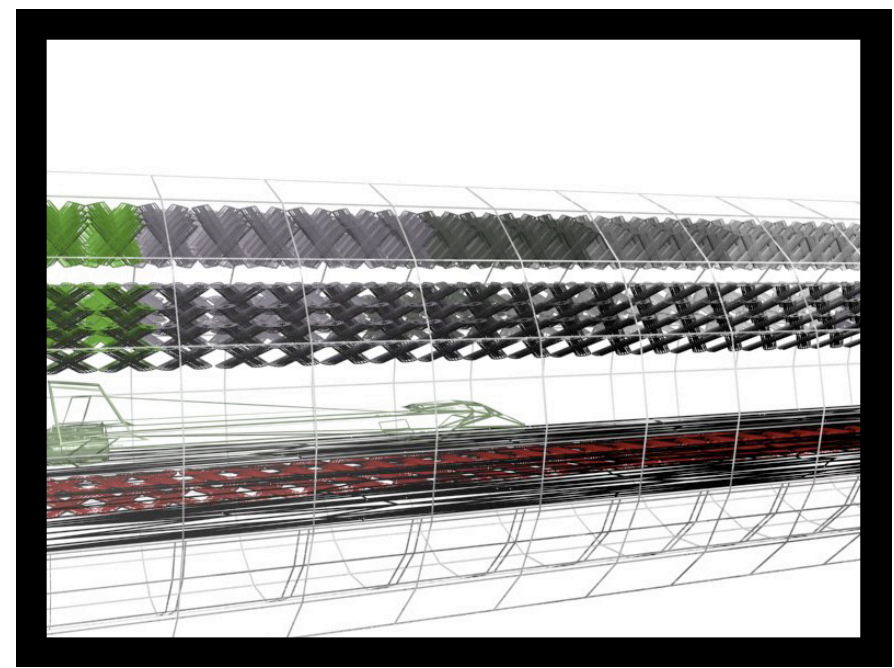

Figure 5. Sideview of proposed craft and guideway system

This horizontal launch approach within the confines of a tunnel, allows the vehicle to attain much higher speeds by minimizing the negative impact of aerodynamic drag. The electrodynamic drag the vehicle would face at low speeds can be controlled using a null flux suspension mechanism, which reduces the power losses in the guideway due to induced current. Such a system can be designed in two distinctive ways:

- A vehicle based design - by using such a method the vehicle is levitated directly over the guideway, and is propelled magnetically using a series of linear synchronous motors (LSM). The magnets within the LSM are AC magnets while those on the vehicle are $\mathrm{DC}$, thereby allowing the magnetic polarity to alternate along the vehicle.

- Mass driver design - by using such a method the vehicle is placed on a purpose built magnetisable stage, which is then levitated and accelerated by the sequential firing of a row of electromagnets. Once the vehicle is accelerated to optimum speed the two 
elements separate and the stage is slowed down and recycled for another launch. After leaving the guideway the vehicle continues to move due to inertia.

The key issue with the mass driver design is that it is only practical for accelerating small objects [4][5][6]. The limitations on the design are imposed primarily by the cost of the silicon to switch current and the cost of the power supply and temporary storage. However, based on such a design if a vehicle weighing approximately 1.5 tonnes was to be accelerated at a speed of 12.5 miles per second (at sea level), it would traverse the 5-mile atmosphere in half a second emerging at a speed of 10 miles per second, enough to escape the solar system[4][5]. Although the launch energy required for such a system seems extremely large, it amounts to roughly $83 \mathrm{MW}-\mathrm{hrs}$, which corresponds to only a few minutes output of any major metropolitan utility plant. Also whereas the length of an effective launcher would exceed 12.5 miles for a $1000 \mathrm{~g}$ acceleration, by providing an attainable $10,000 \mathrm{~g}$ acceleration we can reduce the length to 1.25 miles. It is essential to remember that although energized by capacitors, the costliest and bulkiest energy source known, each capacitor is fired over a hundred times during each launch cycle by being connected to multiple drive coils.

\section{LAUNCH LOCATION \& COST FACTOR}

Once a system design is chosen, the next key step is choosing a construction location. The beauty of a Maglev system is that whilst it may initially be designed for space vehicle launches, it can also be used commercially. By placing such a system closer to the equator the thrust and fuel requirements for sending a vehicle into orbit are lower due to the earth's rotational speed. Also, being closer to the equator the earth's rotational speed provides an added boost to the vehicle's velocity (usually around 6\%). As such, current day systems launched from Cape Canaveral in Florida gain an approximate boost of $911 \mathrm{mph}$ whereas those launched from the French Guinea (5 degrees from the equator) gain roughly a $1000 \mathrm{mph}$ boost. The active magnetic guidance and flexibility in design of the propulsion system allow the guideway to be adapted to various landscape conditions. Current Maglev systems have been tested to withstand sudden gradients up to 10 degrees at an estimated speed of $280 \mathrm{mph}$. However, as the proposed system is enclosed and has operational speeds much greater than $280 \mathrm{mph}$, a sudden gradient of 10 degrees would cause massive g-forces to accumulate. As a result, ideally the system should be built on the side of a mountain, as that would provide the launch system with gradual inclination. The system could also be constructed on a flat plain, but by doing so it would require a larger power input.

Fig. 6 illustrates a \pm 5 -degree section close to equator, which may support the viable launch of a space vehicle using a vacuum based Maglev system. Fig. 7 shows that most countries in that band have either signed or signed and ratified the international space treaty. This means that these countries have committed to exploring and using space for peaceful purposes. By doing so, they have also insured that each country has equal rights to space exploration and habitation. By implementing such a system in any of these developing nations we would not only ensure the economic prosperity of the nation but also a change in the socio-economic background of its people. This is primarily because in order to implement such a system, we would require an international alliance of governments and private investors committed to exploring space for the benefit of mankind. By doing so, we not only ensure that the countries and individuals involved have a viable stake, but also that the system is protected by international agreements and forces throughout its operational life

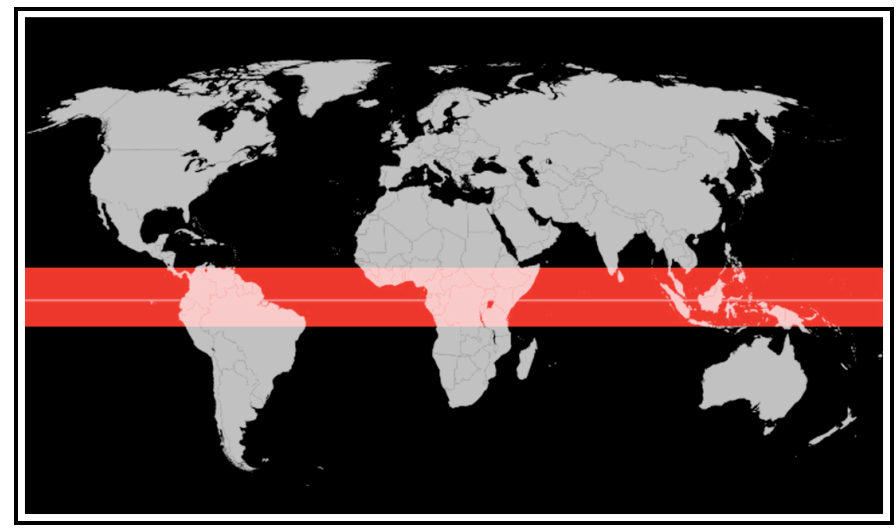

Figure 6. Possible launch locations.

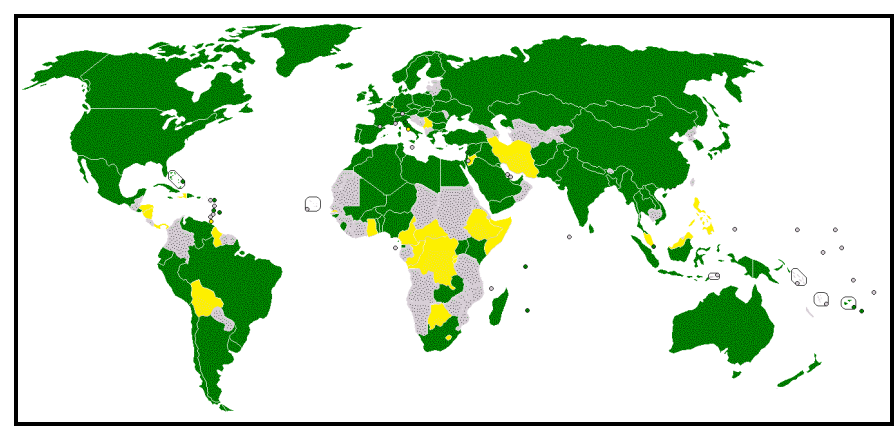

Figure 7. Countries that have signed or ratified the international space treaty

Whilst it is theoretically possible to design an ideal propulsion system and launch vehicle, which is capable of carrying a multitude of payload weights and has an extended life cycle; designs are always limited by the quantity of resources required, overall construction time frames and the system's economic and climatic impact. A large pool of researchers, industry experts and economic analysts are now focusing on lowering the overall cost per launch. In order to better understand the cost performance of current payload launches it is vital to evaluate current launch systems. The main comparison factor for current and future systems is the cost of launching $1 \mathrm{Kg}$ of payload into orbit. The whole concept however is fragile, as launch vehicles often do not have the similar capabilities, characteristics and dimensions. In order to derive the costs for the proposed launch system, exhaustive research has been done into various government space programs, private sector construction projects and upcoming businesses and technologies, which are promoted as low cost alternatives to available systems. These projects enable us to draw a model timeline for the successful completion of the 
project. In order to obtain costs related to the launch vehicle, all costs have been modeled based on NASA budget reports from 2003 to 2009. By doing so, we are able to ensure that we can compare costs derived for the proposed system with existing systems. Furthermore, as the system fabrication is directed towards developing nations, where labor and real estate costs are comparatively cheaper than in the west, for this reason we believe that western capital can be stretched much further. In most developing nations, the average cost of labor is estimated at just over $\$ 1.5$ per day [7]. By providing a higher wage, and implementing incentives for staff such as health care, education and employment opportunities upon the completion of the project, it is believed that the project would attract a more determined and like minded work force, ensuring that minimal delays are incurred.

Before the proposed launch system is employed we must be able to illustrate the various infrastructure components. Within this infrastructure is the construction of a dedicated power plant, the construction of support facilities, guideway housing and guideway. The labor dynamics for the power plant is estimated within the budget request for the station included in the materials and equipment forecast. The budget for facilities is also estimated with the launch system development. For the construction of the chamber and guideway, the personnel needed are calculated as a separate factor in the chamber budget request. From investigation of other large scale construction projects, we can estimate over a 1000 people would be employed and would be deployed in project specific groups. By doing so, the project not only injects foreign currency and revenue into the local economy but it also tackles issues such as local unemployment rates, housing, education and skills specific training, thereby leading to the overall development of the community. As the cost of living and average wages in most developing nations are much lower than the west, we can afford to offer a higher than average wage without compromising the financial stability of the project. To highlight the economic impact of such a project, we can use data collected as part of the Space Shuttle Program (SSP) as a benchmark. In FY 2006, the SSP put nearly $\$ 74.3$ million (including civil service and prime contractor salaries and nonpayroll procurements) into the regional economy. Those expenditures translated into additional economic output, jobs, and income in supporting industries. The total (direct plus indirect and induced8) effect of the SSP on economic output was approximately $\$ 205$ million (less than 1 percent of the nearly $\$ 85$ billion9 in overall economic activity in the 11county region in 2002), \$107 million in personal income, and 1,800 jobs [8].

Furthermore, by adapting the system and the launch vehicle for commercial use, we could generate added revenue by offering hypersonic travel and the experience of weightlessness to paying customers. Based on the overall flight time and launch rates a fee of $\$ 10000$ per flight per passenger could be justified. It should be noted that the fee would offer a $95 \%$ reduction, when compared to the charges imposed Virgin Galatic. The number of passengers per flight could range from 8 to 16 based on the launch vehicle configuration. If 3 such launch vehicles were designed for commercial use with a 10seat configuration, the overall cost would amount to $\$ 1.11$ billion. By operating 20 flights a week, the net revenue would amount to $\$ 2$ million (considering $100 \%$ capacity). This would mean that at full capacity, the system would generate \$104 million in a single financial year. In order to break even on the cost of the 3 launch vehicles it would take just over 10 years. Furthermore, while initial flights will originate and terminate at a single port, the development of another system would open the possibilities of exploring hypersonic travel to cut long-haul flight times by half. Current airlines charge up to $\$ 4500$ for a first class seat on a twelve-hour flight. By offering a similar seat configuration to commercial airlines and halving the overall flight time, it would be possible to compete with the aviation industry and lure premium customers.

The overall budget request for the development of the launch system is $\$ 15.4$ billion spread over a 3 year period, which is lower than NASA's annual space operations budget, estimated at $\$ 16$ billion per annum [2]. This amount includes the total cost of manufacturing the launch vehicle, development costs associated with each mission, and costs associated with payload launch for a total of 25 missions. The budget for the initial manufacturing and testing of the launch vehicle is estimated to be $\$ 620$ million where: $\$ 500$ million is attributed to manufacturing costs and the remainder is associated with test flights [3]. For all future launch system developments the overall cost including test flights would amount to $\$ 370$ million. In order to ensure the overall success of each mission, simulator training and emergency procedure rehearsals are performed prior to each mission, along with test flights to ensure the functionality of the various control systems. This procedure with the necessary upgrades that may be needed for controlling and monitoring of a mission is defined as Checkout and Launch Control System. This is estimated to be around \$2 million for each mission. In every mission a performance monitoring system is employed, ensuring the best possible performance of the launch vehicle and external control mechanisms. The monitoring system relies on a real time communication between the launch vehicle and the control centre, and would be employed to automatically address system anomalies. Whilst the cost of the monitoring system would be mission and flight specific, we estimate the cost at $\$ 855$ thousand per mission. The final procedure of development is the flight management control system, which constantly monitors and adjusts the trajectory and flight dynamics of the launch system. The budget request for this system is estimated at $\$ 12$ million. The Operational Procedures are the main processes that a mission consists of. The ability of the launch vehicle to carry different types of payload is due to operational procedures that provide all the necessary features and specifications for launching the vehicle. The Program Integration procedures assure the successful technical integration of all the craft's elements and payload into each mission to efficiently and effectively meet the customer requirements. The Program Integration budget includes funds for the analysis, management, safety, reliability, maintainability and quality assurance functions that are performed in each mission. The overall budget request is $\$ 45$ million [7]. The final Procedure estimated is the Flight Hardware that ensures the vehicle hardware and software are designed, developed, manufactured, and tested sufficiently to enable the safe and reliable operation of the launch vehicle. 
Flight Hardware and software assures the success of each mission by producing space components to support each mission requirement. The software activities included in this budget include development, formulation and verification of the guidance, targeting and navigation systems software of the craft. The budget request is $\$ 200$ million. In order maintain a low cost system, most aspects discussed above would be preprogrammed and would be part of the launch vehicle development. As such the budget estimates discussed would mainly be one time costs, unless otherwise indicated. Table II provides a cost summary for the various systems mentioned above, and details the time frame of certain budgets and the recurrent nature of others. As various components of the proposed system are at a theoretical design stage, estimated costs have been taken into account.

TABLE II. BUdGet OVERVIEW FOR THE Proposed SySTEM

\begin{tabular}{|l|l|l|}
\hline \multicolumn{2}{|c|}{ Budget Overview for Proposed Propulsion System \& Launch Vehicle } \\
\hline \multicolumn{1}{|c|}{ Action } & \multicolumn{1}{c|}{ Cost (\$ Million) } & \multicolumn{1}{c|}{ Comment } \\
\hline System Development & 1540 & Spread over 3 years \\
\hline MagLev Guideway & 1 & Cost per mile \\
\hline Launch Vehicle R\&D & 500 & For initial development \\
\hline Launch Vehicle Testing & 120 & Over 4 test cycles \\
\hline Launch Control System & 2 & Per planned mission \\
\hline Flight Monitoring System & $0.855^{*}$ & Per planned mission \\
\hline Flight Management System & 12 & One time cost \\
\hline Program Integration & 45 & One time cost \\
\hline Various Software Systems & 200 & One time cost \\
\hline MagLev Housing & 300 & Estimated cost \\
\hline Control center \& Auxilary & 100 & Estimaed cost \\
\hline Labor and trainaing & 150 & Estimated Cost \\
\hline Overheads and Delays & 50 & Estimated Cost \\
\hline \multicolumn{2}{|l|}{ Cost estimated per planned mission for a minimum of 25 missions. }
\end{tabular}

Furthermore it is important to remember that whilst the cost estimates for the proposed system may sound excessive, launch costs for current day systems range from $\$ 50$ million to $\$ 300$ million per flight. Also by utilizing a FRLV and a launch guideway with an average lifespan of fifty years we ensure that the maintenance costs associated with the vehicle are kept to a minimum. It should also be noted that the most attractive feature of such a system is that it can be utilized multiple times each day in all possible weather conditions. The launch rate for such a system is primarily dependent on the amount of funding available for the development of the launch vehicle [3]. Moreover, as this project relies on international cooperation, the net revenue earned from both commercial and space services could be used to fund similar projects in the developing world. It is also essential to keep in mind that as new technologies and innovations enable us to construct a commercial space habitat, the revenue generated by the system would increase exponentially.

\section{CONCLUSION}

With space tourism soon become a reality with the impending retirement of the space shuttle in 2010; ambitious plans for commercial spaceports are beginning to take shape in the United States and around the world. While industry optimists insist that despite the current economic situation, growth in the commercial space sector is inevitable, there is concern that the market for space travel may not be large enough to sustain multiple spaceports. Furthermore, based on the current economic climate and the ever-increasing price of crude oil, future systems must prove their cost effectiveness before obtaining government or private funding. In order to be viable, they must be able to provide a high payload capacity at reduced costs, which can only be achieved by the use of alternative fuels. The launch system and craft proposed in this paper aim at not only bringing the international community together with a common goal, but also help strengthen the socio-economic status of the developing world. This paper highlights not only the various merits of the system, but also provides a financial overview of the project. Even though an overall budget requirement of $\$ 15.6$ billion for the system may seem preposterous, we should remember that NASA, a single government funded space agency has a space operations budget of $\$ 16$ billion per annum [2]. It should also be noted that as the system has minimal maintenance costs, the overall cost per flight, and cost per manned flight, would be significantly cheaper than the current alternatives.

We have now reached a stage, where we as an international community must commit further resources to space exploration and toy with the idea of building a space habitat. By implementing such systems in the developing world, we not only level the playing field but also enable researchers from these countries to engage in future projects. As a community, we must look at the long-term objectives and benefits of any new system, rather than worrying about the initial capital invested. Space tourism is still in its infancy, and as the industry booms it will spearhead innovations of new technologies and materials, which would eventually help us, realize our goals.

\section{REFERENCES}

[1] "NASA FY2005 budget summary request," Jan. 1, 2004. [Online]. URL:www.nasa.gov/pdf/55524main_FY05\%20Agency\%20Summary2.31.pdf [Accessed: Feb. 1, 2009].

[2] "NASA FY2009 budget summary request," Feb. 4, 2008. [Online]. URL:www.nasa.gov/pdf/210020main_NASA_FY09_Budget_Estimates _Summary.pdf [Accessed: Mar. 1, 200̄].

[3] T. Sharma, C. Chatwin, C. Long, R. Young, P. Birch,"Alternative space vehicle launch systems," AIAA Space 2008 Conference \& Exposition, San Diego, California 2008, 2008 AIAA Meeting papers on Disc, vol 13, no. 11 (space), AIAA 2008-7659.

[4] G.K O’Neill, H.H. Kolm,"Mass driver for lunar transport as a reaction engine," Jour. Of Astronomical Sciences, Vol. 15, No. 4, Jan-Mar 1976.

[5] W. Arnold, S. Bowen, S. Cohen, K. Fine, D. Kaplan, J. Newman, et al, "Mass Drivers," part I,II\&III, NASA-AMES Summer Study: "Space Resources and Space Settlements" NASA SP-428, 1979, U.S Govt. printing office.

[6] ESA, "Electromagnetic railgun technology for the deployment of small sub-orbital payloads," ESA Contract No. 13420, September 2003. URL: http://esamultimedia.esa.int/docs/gsp/completed/comp_i_03_N02.pdf . [Accessed: Feb. 1, 2009]

[7] M. Theodoulou, "Low Cost Space Vehicle Launch and Propulsion Systems" MSc. Dissertation, Dept. of Engineering \& Design, University of Sussex, Brighton, UK, 2007.

[8] "Space shuttle program programmatic environmental assessment; transition and program property disposition" Feb. 2008. [Online]. URL: www.nasa.gov/pdf/214131main_SSP_Programmatic_EA_full.pdf. [Accessed: Feb. 10, 2009] 